\title{
História oral e narrativa: tempo, memória e identidades*
}

\author{
Lucilia de Almeida Neves Delgado**
}

\section{Tempo e História}

"Datas

Datas. Mas o que são datas?

Datas são pontas de icebergs.

O navegador que singra a imensidão do mar bendiz a presença dessas pontas emersas, sólidos geométricos, cubos e cilindros de gelo visíveis a olho nu e a grandes distâncias. Sem essas balizas naturais, que cintilam até sob a luz noturna das estrelas, como evitar que a nau se espedace de encontro às massas submersas que não se vêem?" (Bosi, 1992, p. 19)

O tempo é elemento fundamental ao estudo da História. Todavia, afirma Elias: "o tempo não se deixa, ver, tocar, ouvir, saborear, nem respirar como um odor" (Elias, 1998, p. 7). Mas, apesar de aparentemente abstrato, o tempo é uma vivência concreta e se apresenta como categoria central da dinâmica da História.

\footnotetext{
* VI Encontro Nacional de História Oral (ABHO) - Conferência de Abertura

* Professora Titular de Metodologia da História da Pontifícia Universidade Católica de Minas Gerais. Ex-presidente da Associação Brasileira de História Oral.
} 
O tempo é um movimento de múltiplas faces, características e ritmos, que inserido à vida humana, implica em durações, rupturas, convenções, representações coletivas, simultaneidades, continuidades, descontinuidades e sensações (a demora, a lentidão a rapidez). É um processo em eterno curso e em permanente devir. Orienta perspectivas e visões sobre o passado, avaliações sobre o presente e projeções sobre o futuro.

Assim sendo, o olhar do homem no tempo e através do tempo, traz em si a marca da historicidade. São os homens que constroem suas visões e representações das diferentes temporalidades e acontecimentos que marcaram sua própria história. As análises sobre o passado estão sempre influenciadas pela marca da temporalidade. Ao se interpretar a história vivida, no processo de construção da história conhecimento, os historiadores são influenciados pelas representações e demandas do tempo em que vivem e a partir dessas representações e demandas, voltam seus olhos para o vivido reinterpretando-o, sem no entanto o modificar.

Tempo, memória, espaço e história caminham juntos. Inúmeras vezes, através de uma relação tensa de busca de apropriação e reconstrução da memória pela história. A relação tencionada acontece, por exemplo, quando se recompõem lembranças, ou se realizam pesquisas sobre guerras, vida cotidiana, movimentos étnicos, atividades culturais, conflitos ideológicos, embates políticos, lutas pelo poder. Sem qualquer poder de alteração do que passou, o tempo, entretanto, atua modificando ou reafirmando o significado do passado. Sem qualquer previsibilidade do que virá a ser, o tempo, todavia, projeta utopias e desenha com as cores do presente, tonalizadas pelas cores do passado, as possibilidades do futuro almejado. Não é sem razão que Carmelo Distante, recorrendo à voz da poesia afirma:

\footnotetext{
"Não existirá um porvir verdadeiro para humanidade e não existirá um verdadeiro progresso, se o futuro não tiver um 'coração antigo', isto é, se o futuro não se basear na memória do passado" (Distante, 1998, p. 84)
}

Ao se dedicar à análise do passado, o estudioso da História vai ao encontro de um outro tempo diferente daquele no qual está integrado. Nessa viagem realiza-se um amalgama peculiar caracterizado pelo en- 
contro de singularidades temporais. Trata-se do encontro da História já vivida com a história pesquisada, estudada, analisada, enfim, narrada.

A especificidade da História em relação às demais Ciências $\mathrm{Hu}-$ manas e Sociais situa-se no fato de estudar movimentos específicos, únicos em sua manifestação concreta. E o tempo e o espaço são essenciais à definição da especificidade na perspectiva da História. Analisase uma realidade espacial, ou outra realidade espacial. Analisa-se um tempo ou um outro tempo. Em decorrência, para o historiador o estabelecimento de datas e a escolha de cortes cronológicos são tão fundamentais e significativos quanto a definição do tema ou objeto a ser pesquisado.

Na História a dimensão da temporalidade é de tamanha relevância que o próprio tempo é, usualmente, definidor das questões relacionadas às temáticas da pesquisa, pois os interesses por objetos de pesquisa também se alteram com o decorrer do tempo.

Cronologia e calendário, apesar de sua natureza convencional, são instrumentos essenciais ao ofício do historiador. A sucessão irreversível dos meses, anos e séculos constitui-se como um dos elementos referenciais do movimento da História. Representam não somente, de forma simbólica, a permanência e a ruptura peculiares aos processos sociais inerentes à vida da humanidade, como servem de orientação para o ser humano localizar-se na dinâmica temporal à qual, de forma inexorável, encontra-se integrado.

O estudo do nacionalismo, por exemplo, é marcado por enfoques diferenciados ao referir-se a experiências de luta por emancipação nacional pelos países de passado colonial no século XX, ou a experiências totalitárias como a do Nacional Socialismo nesse mesmo século, ou ao se concentrar em manifestações do século XIX, como as dos movimentos tardios de unificação nacional. O mesmo se pode afirmar sobre estudos históricos que se referem a gênero, vida privada, movimentos sociais, condições de trabalho, manifestações políticas, experiências de vida comunitária, religiosidade, entre outros. A escolha do tema está integrada, concomitantemente, à definição de espacial e à de temporalidade, uma vez que são especiais e únicas as realizações humanas no decorrer do tempo, bem como seu interesse por essas experiências.

De acordo com José Carlos Reis (1994, p. 98), o tempo da História não perde de vista a relação entre passado, presente e futuro. 
Privilegia a sucessão, privilegia o evento, procurando inscrevê-lo em alguma ordem. Para o autor, o tempo das Ciências Sociais distingue-se do tempo da História. O primeiro tende mais à simultaneidade dos acontecimentos, tende mesmo a desfazer-se da ordem sucessiva.

Já a História contempla em sua dimensão temporal pelo menos dois aspectos: o da sucessão linear e o da simultaneidade social. A abordagem sucessiva é o que distingue a História da Sociologia. A consideração da simultaneidade é o que as aproxima. Portanto, o tempo social da História é aquele que considera as ações humanas como inscritas em uma simultaneidade interna à sociedade.

Além dessas questões inerentes à categoria tempo e espaço, outras a ela relacionadas contribuem para que sua conceituação alcance grau de complexidade ímpar. Ou seja, na dinâmica da temporalidade o que é específico é também múltiplo. Em outras palavras, se o tempo confere singularidade a cada experiência concreta da vida humana, também a define como vivência da pluralidade, pois em cada movimento da história entrecruzam-se tempos múltiplos, que acoplados à experiência singular / espacial lhe conferem originalidade e substância.

Dessa forma, na história de uma comunidade estudantil universitária de um determinado país, entrecruzam-se temporalidades diversas: a da vida universitária propriamente dita, a da cidade na qual a universidade está inserida, a do país na qual está integrada - e a do movimento estudantil em si mesmo, com suas heterogêneas vivências e a dos estudantes, sujeitos principais desse processo específico.

Cada tempo tem seu substrato e cada substrato temporal inclui em si singularidade e multiplicidade (Neves, 1995, p. 1). O substrato da marca de um tempo é definido pelas ações humanas e pelos valores e imaginário que conformam esse tempo. Portanto, ao buscar identificar, analisar e interpretar os valores e ações humanas de um outro tempo, o historiador, e demais profissionais que elegem a História como área de conhecimento, empreendem um movimento através do qual, como já assinalado, relacionam-se diferentes temporalidades. Tal movimento próprio ao estudo da inter-relação de tempos e não somente da simultaneidade social constituiu característica primordial do ofício de construção do saber histórico.

A complexidade integrante à noção de tempo refere-se às temporalidades múltiplas que se enlaçam, uma vez que as experiências vivi- 
das e a História em transformação são conformadas por processos e acontecimentos. A História como manifestação do fazer coletivo incorpora vivências individuais e, por decorrência, no mínimo duas dimensões: temporal coletiva e temporal individual. Dimensões que, acopladas, conformam experiências únicas, através de uma dinâmica que reconstrói o passado ao tecer sua representação no presente, plasmando em um único enredo a trama das vivências coletivas.

Le Goff afirma:

"A contradição mais flagrante da História é sem dúvida o fato de seu objeto ser singular, um acontecimento, uma série de acontecimentos, de personagens que só existem uma vez, enquanto que seu objetivo, como o de todas as ciências é atingir o universal, o geral, o regular" (Le Goff, 1984, p. 169)

Tempo e acontecimentos relacionados entre si constituem a sucessividade, que é um dos estofos da História. Tempos diversos são identificados pelos elementos substantivos que os fizeram diferentes entre si. A busca do significado de um tempo tem na memória e na própria História suportes básicos. Reconhecer o substrato de um tempo é encontrar valores, culturas, modos de vida, representações, enfim um gama de elementos que, em sua pluralidade, constituem a vida das comunidades humanas.

Em outras palavras, alguns períodos da história da humanidade foram marcados por forte religiosidade, outros por profundo humanismo, alguns por arrojada concepção social e tantos por violência e ceticismo. A singularidade dessas experiências constitui o substrato da marca do tempo. Substrato muitas vezes reafirmado pela memória e em outras por ela sublimado. Cabe aos produtores do conhecimento histórico, mesmo reconhecendo sua amplitude, reconstruí-lo, narrá-lo e interpretá-lo.

Pois conhecer o passado é uma façanha tão extraordinária quanto alcançar o infinito ou contar estrelas, já que, mesmo bem documentado, ele tende a se tornar fugidio e imenso em sua extraordinária dimensão e variedade de situações (Lowenthal, 1981, p. 73). O passado apresenta-se como vidro estilhaçado de um vitral antes composto por inúmeras cores e partes. Buscar recompô-lo em sua integridade é tarefa 
impossível. Buscar compreendê-lo através da análise dos fragmentos é desafio possível de ser enfrentado.

À História e à memória compete buscar empreender tal tarefa. Sua contribuição maior é a de buscar evitar que o ser humano perca referências fundamentais à construção das identidades coletivas, que mesmo sendo identidades sempre em curso, como afirma Boaventura Santos (1994, p. 127-9), são esteios fundamentais do auto-reconhecimento do homem como sujeito de sua história. De uma História que, segundo Valéry, possui propriedades conhecidas que:

"Fazem sonhar, embriagam os povos, engendram neles falsas lembranças, exageram seus reflexos, conservam suas velhas feridas, atormentam-nos no seu repouso, conduzemnos ao delírio de grandezas ou ao da perseguição, tornam as nações amargas, soberbas, vãs, insuportáveis." (Valéry, 1960, p. 935)

Tempo e espaço têm na memória sua salvação. Ambos, de acordo com D'Aléssio, confundem-se no resgate das lembranças (D’Aléssio, 1998, p. 272). Ambos são esteios das identidades. São suportes do ser no mundo. São referenciais que tornam os homens sujeitos de seu tempo. Para a autora há sempre um entrelaçamento entre espaço e memória. Para reforçar sua idéia, reporta-se a Poulet, que afirma:

“Graças à memória, o tempo não está perdido, e se não está perdido, também o espaço não está. Ao lado do tempo reencontrado está o espaço reencontrado ou para ser mais preciso, está um espaço, enfim reencontrado, um espaço que se encontra e se descobre em razão do movimento desencadeado pela lembrança." (Poulet, 1992, p. 54-5)

Mas se o espaço se transforma e as referências espaciais se perdem na dinâmica incessante do tempo, os homens perdem seus elos, sua base identitária e a substância de sua história.

“[...] a angústia vem com mais freqüência: a angustia de ver a mobilidade dos lugares acelerar ainda mais a mobilidade do nosso ser, já tão assustadora por si mesma. Pois como não perder a fé na vida, quando se percebe que é ilusória a única fixidez em que se acreditava: a fixidez dos lugares, dos obje- 
tos ali situados? A mobilidade dos lugares rouba nosso último recurso.” (Poulet, 1992, p. 11)

Enfim, os homens como sujeitos da História e de sua temporalidade podem produzir acontecimentos e mudanças, ou impedi-los de se concretizarem. Podem construir referências ou destruí-las. Podem reafirmar o poder, ou contestá-lo, podem tolher a liberdade do ser ou reafirmá-la.

\section{Memória: significados e relações}

“'Toda consciência do passado está fundada na memória. Através das lembranças recuperamos consciência dos acontecimentos anteriores, distinguimos ontem de hoje, e confirmamos que já vivemos um passado." (Lowenthal, 1981, p. 75)

Júlio Pimentel Pinto afirma que "a memória é esse lugar de refúgio, meio histór ia, meio ficção, universo marginal que permite a manifestação continuamente atualizada do passado" (Pinto, 1998, p. 307). $\mathrm{Na}$ verdade, a imbuída de vastas possibilidades, a memória torna-se infinitamente rica em suas manifestações.

Reportando-nos a Paul Thompson e com ele dialogando, podemos inferir, que através da ativação, espontânea ou não, do ato de relembrar os homens podem:

- reacender e reviver utopias e sonhos de um tempo anterior que marcou suas vidas individuais ou comunitárias;

- reconstruir a atmosfera de outros tempos, relembrando hábitos, valores, e práticas da vida cotidiana;

- reacender emoções de diferentes naturezas: individuais, sociais, políticas, culturais;

- relembrar convivências mútuas que se constituíram na dinâmica da História;

- representar e reativar correntes de pensamento;

- reviver embates políticos e ideológicos;

- reconstituir climas de religiosidade, de lazer, de companheirismos, de lutas.

Portanto, tal como apreender a amplidão do passado é um desafio para o ser humano, ativar a memória também o é, pois a memória, 
além de incomensurável, é mutante e plena de significados de vida, que algumas vezes se confirmam e usualmente se renovam.

São inúmeras as concepções de memória. Para Marilena Chauí, "a memória é uma evocação do passado. É a capacidade humana de reter e guardar o tempo que se foi, salvando-o da perda total" (Chauí, 1995, p. 125). Tempo e memória, portanto, constituem-se em elementos de um único processo, são pontes de ligação, elos de corrente, que integram as múltiplas extensões da própria temporalidade em movimento. A memória por sua vez, como forma de conhecimento e como experiência, é um caminho possível para que sujeitos percorram a temporalidade de suas vidas. Para Bobbio essa possibilidade é tão significativa que, ao refletir sobre o ato de rememorar, constata:

"O relembrar é uma atividade mental que não exercitamos com freqüência por que é desgastante ou embaraçosa. Mas é uma atividade salutar. $\mathrm{Na}$ rememoração reencontramos a nós mesmos e a nossa identidade, não obstante muitos anos transcorridos, os mil fatos vividos. [...] Se o futuro se abre para a imaginação, mas não nos pertence mais, o mundo passado é aquele no qual, recorrendo a nossas lembranças, podemos buscar refúgio dentro de nós mesmos, debruçarnos sobre nós mesmos e nele reconstruir nossa identidade" (Bobbio, 1997)

Em tempos passados os homens já identificavam a importância da memória como suporte construtor de identidades e solidificador das consciências. Santo Agostinho, considerando a importância da memória, definiu-a como uma das categorias fundamentais da alma humana. A mitologia grega, por sua vez, integrou a memória ao quadro de suas representações. Dessa forma, Menemosyne é mãe das musas que protegem a história e a arte. História que é a construção da experiência humana através dos tempos. Arte, que traduz o sentimentos e emoções dos seres humanos e representa os valores e as expectativas de um época.

A identificação metafórica da memória com o oceano (profundo e imenso) relaciona-se ao fato de ser a memória inseparável da vivência da temporalidade, do passar e escoar do tempo, tornando os homens seres perecíveis enquanto indivíduos, mas possivelmente perenes enquanto comunidade histórica. Em outras palavras, a memória atualiza 
e presentifica o passado, uma vez que é retenção, mesmo que inconsciente ou encoberta da experiência vivida e dos sentimentos preservados.

Os conceitos e significados da memória são vários, pois a memória não se reduz ao ato de recordar. Revelam os fundamentos da existência, fazendo com que a experiência existencial, através da narrativa, integre-se ao cotidiano fornecendo-lhe significado e evitando, dessa forma, que a humanidade perca raízes, lastros e identidades (Todorov, 1999, p. 26-7).

Para Marieta Ferreira, a memória "é construção do passado pautada por emoções e vivências. É flexível e os eventos são lembrados à luz da experiência subseqüente e das necessidades do presente" (Ferreira, 2000, p. 111). Dessa forma, o conceito de memória não é homogêneo e conforma-se por múltiplos significados, entre os quais se destacam:

- ordenação e releitura de vestígios (espontânea ou induzida), relacionada a comportamentos, mentalidades, valores;

- retenção de elementos inerentes a conhecimentos adquiridos;

- estabelecimento de nexos entre o presente e as experiências vividas;

- evocação do passado, através de reminiscências e lembranças;

- afirmação de identidades através do reconhecimento da pluralidade e da alteridade, que conformam a vida em fluxo contínuo;

- atualização do passado no eterno presente;

- retenção e manifestação, através do ato de relembrar de reminiscências vagas, telescópicas, profundas, transparentes, auto-censuradas, registradas, esquecidas, selecionadas;

- evocação de utopias, que libertam o homem, fazendo do passado suporte para reconstrução do próprio presente e para construção do futuro;

- manifestação de identidades - não unívocas, mas plurais, múltiplas e sempre atualizadas.

- reconhecimento, ou mesmo superação de traumas marcados pela ausência de raízes;

- reconhecimento de espaços perdidos ou reencontrados.

Significados tantos e tão potencializadores que confluem às dimensões superiores da vida: humanista em sua essência; dialética em sua propensão transformadora; dilacerada, múltipla e plural, em sua sociabilidade. 
A memória contém incomensuráveis potencialidades, destacando-se o fato de trazer consigo a forte marca dos elementos fundadores, além dos elos que conformam as identidades e as relações de poder. São as lembranças - em suas dimensões mais profundas - que conformam as heranças e acumulam os detritos, que segundo a tradição bejaminiana, refundam mitos de origem e alimentam o cortejo triunfante dos vencedores de todas as épocas.

Para Margarida Neves, o conceito de memória é abrangente e polifônico em todas a suas potencialidades:

"O conceito de memória é crucial porque na memória se cruzam passado, presente e futuro; temporalidades e espacialidades; monumentalização e documentação; dimensões materiais e simbólicas; identidades e projetos. É crucial porque na memória se entrecruzam a lembrança e o esquecimento; o pessoal e o coletivo; o individuo e a sociedade, o público e o privado; o sagrado e o profano. Crucial porque na memória se entrelaçam registro e invenção; fidelidade e mobilidade; dado e construção; história e ficção; revelação e ocultação." (Neves, 1998, p. 218)

Entre memória e História existe uma clara distinção, que se contrapõe ao senso comum que "insiste em sua indiferença (como no slogan, "um país sem memória é um país sem história')" (Brandão, 2001, p. 3).

Todavia, não há oposição, mas tão somente diferenças entre ambas, o que as aproxima são as construções das identidades, que têm o passado como suporte e a potencialidade visionária do porvir e do poder como possíveis objetivos. O que as distingue são suas naturezas e estratégias.

A memória, mais relacionada à ficção do que a História, define relevância a tudo que evoca o que passou, garantindo sua permanência reatualizada, ou mesmo ressignificada no presente. A memória, portanto, de acordo com Nora, encontra-se em múltiplos lugares - os lugares da memória (Nora, 1984).

Materializa-se no esforço das coletividades para não se perder no esquecimento e no eterno presente. São os homens memoriosos, os narradores, reportando-nos a Borges, que fazem dos romances, poe- 
mas e biografias, lugares da memória. São os profissionais da história, os museólogos, os arquivistas responsáveis pela preservação de vestígios e fragmentos do que passou, que fazem dos museus, arquivos e centros de documentação, lugares da História.

Os acontecimentos da vida em comunidade, e mesmo das experiências mais solitárias da vida humana, são sinais exteriores, são estímulos para o afloramento de lembranças e reminiscências, que constituem o estofo do tempo da memória: individual, local, comunitária, regional, nacional ou mesmo internacional.

$\mathrm{Na}$ dinâmica do relembrar, estimulado por sinais exteriores, o homem memorioso reconstitui referências tais como: no tempo do rádio, na década de 1960, na época dos Beatles, quando eclodiu a grande guerra, quando as famílias temiam o comunismo, quando a prefeitura construiu aquela ponte, no tempo em que cortaram as árvores da cidade, quando os bondes enfeitavam as ruas, na época da guerra do Vietnam, quando os pacifistas saíram às ruas.

A memória, em sua extensa potencialidade, ultrapassa, inclusive, o tempo de vida individual. Através de histórias de famílias, das crônicas que registraram o cotidiano, das tradições, das histórias contadas através de gerações e das inúmeras formas de narrativas, constrói-se a memória de um tempo que antecedeu ao da vida de uma pessoa. Ultrapassa-se a cronologia atual e o homem mergulha no seu passado ancestral. Nessa dinâmica, memórias individuais e memórias coletivas encontram-se, fundem-se e constituem-se como possíveis fontes para a produção do conhecimento histórico.

\section{História e Memória: representações do passado em permanente mobilidade}

Para Marc Bloch, a "História é a ciência dos homens no tempo" (Bloch, 1957, p. 26). Mas, não só a História enquanto dinâmica inscreve-se no tempo. As concepções de História, que são polissêmicas, também estão a ele relacionadas e carregam suas marcas, suas nuanças.

$\mathrm{Na}$ Grécia a História traduziu-se por uma concepção reflexiva e metodológica. Em Roma destacou-se por seu caráter utilitário, patriótico e moral. Na Idade Média retomou uma perspectiva filosófica, 
abstrata e, de certa forma, transcendental. Com o Renascimento explodiu em humanismo e antropocentrismo seculares. No período do iluminismo foi reconhecida como fonte de conhecimento, contraposta à tradição e afirmativa da razão. O Positivismo buscou transformá-la em área específica de conhecimento, neutra, descritiva e com fronteiras bem definidas. $\mathrm{O}$ marxismo afirmou sua dinâmica através de relação dialética entre a vida material e a vida social. A Escola dos Annales rompeu fronteiras, adotou a interdisciplinaridade, renovou metodologias e temáticas, além de incorporar uma nova forma de narrativa, à qual se acopla a reflexão.

A História conhecimento em sua expressão policromática, portanto, é:

- produção intelectual do saber;

- práxis interpretativa da realidade;

- reflexão sobre si mesma;

- área de conhecimento sujeita a verificação, através de metodologias, pesquisa documental, construção de evidências;

- espaço institucional do saber;

- produto social, caracterizado pela crítica sobre si mesmo;

- conjunto organizado de produção de memórias;

- narrativas que se contrapõem ao efêmero.

Para alguns historiadores, dentre os quais se destaca Nora, no coração da História trabalha um criticismo destruidor da memória espontânea. Na verdade, a relação da História com a memória é bem mais complexa, e envolve, concomitantemente, apropriação, diálogo, destruição e contribuição.

Tanto a História como a memória, apesar de distintas, possuem um substrato comum: são antídotos do esquecimento. São fontes de imortalidade. Em decorrência, como afirma Le Goff, são também espaços de poder.

Para os que identificam a História como destruidora da memória, os seguintes argumentos sustentam sua convicção:

- a tradição histórica é exercício regulador da memória;

- a História transforma a paisagem da memória espontânea, transformando-a em história institucional;

- a História científica contrapõe-se à espontaneidade e subjetividade da memória; 
- o peso social da História enquadra a memória;

- a História é espaço de poder que também produz memórias, mas memórias dirigidas.

Em contrapartida, os que identificam a História como alimento da memória e vice-versa, concluem que:

- a História enriquece as representações possíveis da memória coletiva;

- a História fornece símbolos e conceitos para que a sociedade pense sobre si mesma e sobre sua relação com o passado;

- ao oferecer instrumentos para preservação da memória social, a História contribui para sua recuperação e difusão;

- a História, através da narrativa, fertiliza a memória, contribuindo para reativação das lembranças;

Considerando esse elenco de argumentos podemos afirmar que, de fato, não há oposição, mas sim alteridade entre memória e História, sendo que a construção das identidades e a representação do passado as aproximam. Portanto, não é sem razão que Guarinello constata: “A oposição entre memória e História é em grande parte ao menos falsa e oculta uma outra oposição, ao meu ver igualmente inexata, entre cultura erudita e cultura popular"' (Guarinello, 1994, p. 192).

\section{Sujeito, narrativa e história: \\ o olhar da memória}

"Trata-se de imaginar a narrativa como esta linha que caminha para frente, mas que é capaz de aceitar reviravolta e interrupções. Uma linha que pode se desdobrar em três, quatro, dez, quadros. Quadros com um desenvolvimento relativamente autônomo. Quadros que podem parar, recuar em relação à linha fundamental, e que se relacionam entre si, formando uma espécie de teia, capaz de enredar a narrativa" (Araújo, 1998, p. 244)

As narrativas, tal qual os lugares da memória, são instrumentos importantes de preservação e transmissão das heranças identitárias e das tradições. Narrativas sob a forma de registros orais ou escritos são 
caracterizadas pelo movimento peculiar à arte de contar, de traduzir em palavras as reminiscências da memória e a consciência da memória no tempo. São importantes como estilo de transmissão, de geração para geração, das experiências mais simples da vida cotidiana e dos grandes eventos que marcaram da História da humanidade. São suportes das identidades coletivas e do reconhecimento do homem como ser no mundo. Possuem natureza dinâmica e como gênero específico do discurso integram a cultura de diferentes comunidades. São peculiares, incorporam dimensões matérias, sociais, simbólicas e imaginárias. Plenas de dimensão temporal tem na experiência sua principal fonte (Benjamin, 1994, p. 98).

As narrativas possuem a potencialidade de fazer viajar o ouvinte através da viagem narrada. Como fontes para construção do conhecimento histórico, seu potencial é inesgotável, pois também, como afirma Benjamin, "incorporam as coisas narradas à experiência dos seus ouvintes". Em outras palavras, possibilitam "pontuar entre o momento da fala e o eternizar da escrita, desvãos que vazam no tempo o sentido da existência" (Grossi \& Ferreira, 2001, p. 26).

No tempo presente, no mundo marcado pela cultura virtual e pela velocidade muitas vezes descartável das informações, tendem a desaparecer os narradores espontâneos, aqueles que fazem das lembranças, convertidas em casos, lastros de pertencimento e sociabilidade. Nessa dinâmica de velocidade incontida, desenfreada, perdem-se as referências, diluem-se os substratos da vida, reduzem-se as possibilidades de construção do saber.

A comunidade acadêmica, preocupada com a transmissão das heranças do passado que possam servir como esteios para o futuro, tem buscado criar alternativas para que o registro da fala de narradores, anônimos ou não, possa funcionar como um dos elos entre o que passou e o que ficou, possa se transformar no olhar do tempo presente sobre as experiências do tempo ido, mas não mais perdido. A narrativa contém em si força ímpar, pois é também instrumento de retenção do passado e, por conseqüência, suporte do poder do olhar da memória.

Os melhores narradores são aqueles que deixam fluir as palavras na tessitura de um enredo que inclui lembranças, registros, observações, silêncios análises, emoções, reflexões, testemunhos. São eles su- 
jeitos de visão única, singular, porém integrada aos quadros sociais da memória e da complexa trama da vida.

A história oral é uma metodologia primorosa voltada à produção de narrativas como fontes do conhecimento, mas principalmente do saber. Dessa forma, "a razão narrativa desemboca no saber contar um fato real ou imaginário, despertando no ouvinte o desejo de significar experiências vividas, que não retornam mais" (Grossi e Ferreira, 2001, p. 30).

Por ser uma experiência através da qual se compartilha o registro das lembranças, transforma a narrativa em processo compartilhado que inclui em si as seguintes dimensões: estímulo ao narrar, ato de contar e relembrar e disponibilidade para escutar. Fala, escuta e troca de olhares compõem a dinâmica desse processo único e essencial à vida humana, pois não se vive em plenitude sem a possibilidade escutar, de contar histórias e de se apreender sob a forma de conhecimento, ou melhor, de sabedoria, o conteúdo narrado.

As narrativas produzidas pela história oral incluem-se entre as narrativas históricas, que se distinguem das narrativas épicas, que são lendárias, atemporais. Ou seja, as narrativas históricas referem-se a "[um tempo pesquisável e pesquisado], com referências cronológicas passíveis de serem encontradas, que trata do tempo mais recente do homem" (Gagnebin, 1997, p. 19).

As narrativas são traduções dos registros das experiências retidas, contêm a força da tradição e muitas vezes relatam o poder das transformações. História e narrativa, tal qual História e memória, se alimentam.

Narrativa, sujeitos, memórias, histórias e identidades. São a humanidade em movimento. São olhares que permeiam tempos heterogêneos. São a História em construção. São memórias que falam.

\section{Referências bibliográficas:}

ARAÚJO, Ricardo Benzaquen. História e Narrativa. In: MATTOS, Ilmar Rohloff (org.). Ler e Escrever Para Contar: Documentação, Historiografia e Formação do Historiador. Rio de Janeiro: Access Editora, 1998.

BENJAMIN, Walter. Obras escolhidas: magia e técnica, arte e política. São Paulo: Brasiliense, 1994.

BLOCH, Marc. Introdución a la Historia. México / Buenos Aires: Fondo de Cultura Económica, 1957. 
BOBBIO, Noberto. O Tempo da memória. Rio de Janeiro: Campus, 1997. BOSI, Alfredo (org.). Tempo e História. São Paulo: Companhia das Letras, 1992. BRANDÃO, Jacyntho Lins. A Justa Memória: Paul Ricouer explora as relações entre memória, história e esquecimento. Jornal de Resenhas. São Paulo: Folha de São Paulo / Discurso, 12 de maio de 2001.

CHAUÍ, Marilena. Convite à Filosofia. São Paulo: Ática, 1995

D'ALÉSSIO, Márcia Mansor. Intervenções da Memória na Historiografia: identidades, subjetividades, fragmentos, poderes. Projeto História (17). São Paulo: EDUC, 1998.

DISTANTE, Carmelo. Memória e Identidade. Tempo Brasileiro (95). Rio de Janeiro: Tempo Brasileiro, 1992

ELIAS, Nobert. Sobre o Tempo. Rio de Janeiro: Jorge Zahar, 1998.

FERREIRA, Marieta Morais. História do Tempo Presente: desafios. Cultura Vozes v. 94, n. 3. Petrópolis: Vozes, 2000.

GAGNEBIN, Jeanne Marie. Sete aulas sobre Linguagem, Memória e História. Rio de Janeiro: Imago, 1997.

GROSSI, Yonne e FERREIRA, Amauri. Razão narrativa: significado e memória. História Oral (4). São Paulo: ABHO, 2001.

GUARINELLO, Norberto Luiz. Memória Coletiva e História Científica. In: Revista Brasileira de História (28). São Paulo: ANPUH, 1994.

LE GOFF, Jacques. Memória - História. Lisboa: Imprensa Oficial/ Casa da Moeda, 1984.

LE GOFF, Jacques. História e Memória. Campinas: Editora da UNICAMP, 1990.

LOWENTHAL, David. Como Conhecemos o Passado. Projeto História (17). São Paulo: EDUC, 1981.

NEVES, Lucilia de Almeida. Nacionalismo: substrato da marca de um tempo. In: Anais do VI seminário sobre economia mineira. Belo Horizonte: UFMG/CEDEPLAR, 1995.

NEVES, Margarida de Souza. História e Memória: os jogos da memória. In: MATTOS, IImar Rohloff (org.). Ler e escrever para contar: documentação, historiografia e formação do historiador. Rio de Janeiro: Access, 1998.

NORA, Pierre. Lês Lieux de Memórie. I: La Republique. Paris: Gallimard, 1984.

PINTO, Pimentel Júlio. Uma memória do mundo: ficção, memória e história em Jorge Luís Borges. São Paulo: Estação Liberdade, 1998.

POULET, G. O Espaço Proustiano. Rio de Janeiro: Imago, 1992.

REIS, José Carlos. Tempo, História e Evasão. Campinas: Papirus, 1994.

SANTOS, Boaventura. Pela Mão de Alice: o social e o político na pós modernidade. Lisboa: Edições Afrontamentos, 1994. 
TODOROV, Tzvetan. O homem desenraizado. Rio de Janeiro: Record, 1999. VALÉRY, Paul. Del'historie. In: Regards sur lê monde actuel. Ouveres II. Paris: Bibliothèque de la Plêiade, 1960.

Resumo: O texto compreende a análise da inter-relação memória e História, adotando, em primeiro plano, como eixo de abordagem, a dimensão da temporalidade e o conceito de tempo no processo histórico e também nas narrativas, que se constituem como fontes orais sobre a dinâmica da História, compreendida principalmente por sua dimensão social, através da qual diferentes sujeitos individuais e coletivos se relacionam, construindo o movimento peculiar dos homens no tempo. Também realiza uma análise da metodologia da história oral, como narrativa (versão e testemunho), como suporte e como meio de construção e reconstrução da memória que se constitui em fonte de conhecimentos sobre processos históricos específicos e em substrato (memória revivida) de construção de identidades individuais e coletivas.

Palavras-chave: Memória; história oral; tempo; espaço; identidades; narrativa.

Oral history and NarRative: tIME, memory and IDENTITIES

Abstract: Systematic and methodic analysis about links between time and history, memory and history (meanings, symbols and past representations); space and identities; descriptions memory and history actors

Key words: Memory; oral history; time; space; identities; descriptions. 